\title{
Representações de gênero nas relações estudante de enfermagem e cliente: contribuições ao processo de ensino-aprendizagem
}

Gender representations in nursing student and client relations: contributions to the learning process

Representaciones de género en las relaciones estudiante de enfermería y cliente: contribuciones al proceso enseñanza-aprendizaje

Renata de Lima Muroya', Daniela Auad', José Roberto da Silva Brêtas'

'Universidade Federal de São Paulo. Departamento de Enfermagem. Grupo de Estudos Corporalidade e Promoção da Saúde. São Paulo, SP

Submissão: $27 / 10 / 2009$

Aprovação: 14/08/2010

RESUMO

O objetivo do estudo foi Identificar, conhecer e aprofundar o conhecimento sobre as relações de gênero entre estudantes e clientes na prática do cuidado de enfermagem. Estudo de abordagem Qualitativa fundamentado nos pressupostos da representação social e analisado à luz dos referenciais teóricos de gênero. Utilizou-se a técnica Teoria do Núcleo Central. Os resultados foram organizados em uma árvore máxima a partir da Qual emergiram como elementos periféricos dois eixos temáticos: "A tríade igualdade/diferença/desigualdade no cuidado de enfermagem" e "A falta de preparo: a lacuna no ensino". Os resultados expressam uma dificuldade por parte dos(as) estudantes em prestar cuidado ao gênero Que não é o seu; revelam um discurso ancorado na percepção das diferenças sexuais e na crença de uma heterossexualidade presumida.

Descritores: Corpo; Educação em enfermagem; Estudantes de enfermagem; Identidade de gênero; Sexualidade.

\section{ABSTRACT}

The purpose of the study was to identity, to know, and to improve the knowledge about the relationships of gender among the students and the clients in the practice of nursing care. That was a Qualitative study, based in the theory of social representation and analyzed concerning the gender theoretical references. Concerning the data base made, based in the technique of Central Core Theory. The results were organized in a "tree". Two main thematic ways were arisen as second interest elements: "The triad equality/difference/ineeuality in the nursing care" and "The lack of knowledge: a gap in the learning process". The results have showed a students' difficulty in the process to take care a patient who has a different gender of theirs; showed a speech based in the perception of the gender differences and in the belief of heterosexuality presumed.

Key words: Human body; Education, nursing; Students, nursing; Gender identity; Sexuality.

\section{RESUMEN}

El objetivo del estudio fue identificar, conocer y profundizar los conocimiento sobre las relaciones de género entre estudiantes y clientes en la práctica del cuidado de enfermería. Estudio de abordaje cualitativa fundamentado en los presupuestos de la representación social y analisado bajo la luz de los referenciales teóricos de género. Se utilizó la técnica Teoría del Núcleo Central. Los resultados fueron organizados en un árbol máxima a partir de la cual emergieron como elementos periféricos dos ejes temáticos: "La triade igualdad/ diferencia/desigualdad en el cuidado de enfermería" y "La falta de preparación: la laguna en la enseñanza". Los resultados expresan una dificultad por parte de los (las) estudiantes en prestar cuidado al género que no es el suyo; revelan un discurso basado en la percepción de las diferencias sexuales y el la creencia de una supuesta heterosexualidad.

Descriptores: Cuerpo humano; Educación en enfermería; Estudiantes de enfermería; Identidad de género; Sexualidad. 


\section{INTRODUÇÃO}

Ao abordar as relações de gênero na área da enfermagem, não se pode desconsiderar a formação histórica dessa profissão, pois sabemos Que continua sendo uma profissão predominantemente feminina, ainda Que o número de homens em seu Quadro profissional tenha aumentado, a profissão, por vezes, é encarada como simples trabalho de mulher ${ }^{(1)}$.

Nessa perspectiva, há uma tendência em associar o cuidado exclusivamente ao universo feminino, ou seja, a interpretação do cuidado como representativo da enfermagem no sentido de "maternagem" e significando-o como "essência feminina". Esta visão reforça o preconceito existente demonstrando que tudo o Que é ligado ao sexo feminino é menos importante ${ }^{(2)}$.

Segundo Bandeira e Oliveira ${ }^{(3)}$, cuidar é atribuído como tarefa de mulher (enfermeira, mãe, professora, assistente social), tratar/curar é tarefa de homem (médico, pai, provedor). Isto posto, gera uma dicotomização entre cuidar e curar, o Que acaba definindo uma série de outros conflitos, de relações de poder e de hierarquia Que estabelecem na prática profissional da enfermagem.

Desta forma, ao utilizar a categoria gênero como lente possível para interpretar essa realidade, as relações de gênero se tornam a novidade Que possibilita fazer a mediação entre a área da saúde e a das ciências sociais, para pensar o conjunto das relações sociais na sua simultaneidade. A ótica de gênero possibilita pensar na Questão da igualdade e diferença entre os sexos ${ }^{(4)}$.

A desconsideração das relações de gênero concorre para a existência de lacunas na formação profissional para lidar com a diversidade da prática profissional. Trata-se de não preparar o(a) estudante para atender a mulheres vítimas de violência; para realizar orientação à saúde para aos(às) diversos(as) clientes Que possuem uma orientação do desejo sexual diferente daquela considerada como "padrão heterossexual"; para atender um(a) travesti/transexual ao chamá-lo(a) na fila de espera.

Ao realizar um levantamento bibliográfico nas principais bases de dados de enfermagem, foram encontrados poucos trabalhos Que abrangem a temática "Gênero e Educação em enfermagem"(5-14). Não foi encontrada literatura Que abordasse exclusivamente a categoria gênero na análise das práticas e das narrativas dos(as) estudantes de enfermagem. As únicas pesquisas Que tiveram como sujeito de estudo os(as) estudantes de enfermagem abordam Questões como: a sexualidade ${ }^{(15-16)}$; regimes de verdade Que perpassam a enfermagem e são manifestados por estudantes de graduação ${ }^{(11)}$; e preconceito de gênero entre estudantes de enfermagem ${ }^{(13)}$.

Nessa perspectiva, trabalhos Que articulam gênero, saúde e educação, contribuem para compreender e delimitar redes de poder Que se colocam em movimento com determinados conhecimentos, ênfases educativas, instrumentos de diagnósticos e modos de assistir e educar mulheres, homens e crianças ${ }^{(6)}$.

Assim, é importante salientar a amplitude Que a adoção da categoria gênero possibilita para entender determinadas práticas de assistência à saúde e de enfermagem, além do alcance e conseQüências de políticas públicas de saúde, propiciando desta forma uma visibilidade maior para possíveis desigualdades de gênero.

Desta forma, com base no contexto apresentado e na literatura científica, formulou-se o seguinte problema: Como as desigualdades existentes nas relações de gênero influenciam o cuidado prestado à(ao) cliente pela(o) estudante de enfermagem e quais consequências isso tem para o ensino e prática da enfermagem?

Utilizou-se um recorte da teoria das relações de gênero, contemplando, desta forma, a categoria gênero como lente possível para conhecer o objeto, o Qual se caracteriza pelas relações de gênero entre estudante e cliente na prática do cuidado de enfermagem. Desta forma, encontramos respaldo no referencial teórico de Joan Scott e outras autoras nacionais, tais como Guacira Lopes Louro e Dagmar E. Meyer. Essas autoras possuem a mesma abordagem de Scott e estão relacionadas com o objeto de pesquisa do presente trabalho.

\section{OBJETIVO}

Identificar, conhecer e aprofundar o conhecimento sobre as relações de gênero entre estudantes e clientes na prática do cuidado de enfermagem. Analisar como as relações de gênero são construídas, legitimadas, contestadas e mantidas no discurso dos (as) estudantes na relação com a (o) cliente no Que concerne à prática do cuidado de enfermagem.

\section{MÉTODOS}

Tratou-se de um estudo com abordagem Qualitativa, fundamentado nos pressupostos da representação social para subsidiar a apreensão e análise das relações de gênero emergentes da prática do cuidado prestado pelo estudante de enfermagem ao cliente. O objeto de estudo nesta pesquisa refere-se às relações de gênero no contato entre estudante-cliente na prática do cuidado de enfermagem.

Para construção das representações sociais é necessário a criação de dois mecanismos essenciais Que transformam o não-familiar em familiar, transferindo-o para nossa própria esfera particular para depois reproduzi-lo entre as coisas Que nós podemos ver e tocar, e, conseQuentemente, controlar. O primeiro deles é denominado "ancoragem", o Qual tem como objetivo ancorar idéias estranhas e reluzi-las a categorias e imagens comuns. O segundo mecanismo, denominado "objetivação", tem como objetivo transformar algo abstrato em algo Quase concreto, transferir o Que está na mente em algo Que exista no mundo físico. Objetivar é descobrir a Qualidade icônica de uma idéia, é reproduzir um conceito em uma imagem ${ }^{(17-18)}$.

Estabelecendo uma ponte entre a metodologia das representações sociais a ser usada e o referencial teórico adotado, encontra-se respaldo em Arruda $^{(19)}$ ao estabelecer algumas associações das teorias de gênero com a teoria das representações sociais, nos revelando Que ambas tecem uma crítica ao binarismo Que antepõe natureza e cultura, ração e emoção, objetivo e subjetivo, pensamento e ação, ciência e senso comum. Estas duas teorias afirmam a importância das dimensões subjetiva, afetiva e cultural na construção do saber e nas ações humanas, e a importância de considerá-las na construção do conhecimento e no fazer científico.

O presente estudo foi realizado a partir de um "conjunto de dados”, o Qual é constituído por 35 entrevistas não-estruturadas, gravadas e transcritas, totalizando 243 páginas impressas, Que versam sobre a relação estudante-cliente na prática do cuidado de enfermagem. Essas entrevistas foram realizadas com estudantes de um curso de graduação em enfermagem de uma universidade pública na cidade de São Paulo, mais especificamente com 28 estudantes do 
sexo feminino e sete estudantes do sexo masculino, no período de agosto de 2004 a julho de 2006.

Não houve predeterminação daQueles Que deveriam ser entrevistados, QualQuer estudante Que estivesse regularmente matriculado no curso de enfermagem da referida instituição e Quisesse participar poderia ser entrevistado. A abordagem consistiu na colocação da pesquisa e o seu assunto. Caso a pessoa abordada aceitasse, era entrevistada imediatamente ou posteriormente em horário agendado.

Quanto ao tipo de instrumento e roteiro utilizado, foi utilizada entrevista aberta, com roteiro não estruturado, somado ao uso de gravador, após consentimento. As perguntas norteadoras foram: "Levando em conta as vivências dos estágios, como você percebe o corpo do cliente e como é a sua relação com este corpo Que recebe os cuidados de enfermagem?", "Quando presta cuidados, você se sente invadindo a intimidade do cliente?", e "Como você se sente ao cuidar do corpo de um (a) cliente?".

A presente pesquisa foi submetida ao CEP-UNIFESP e recebeu sendo aprovado pelo protocolo número 1766/07, atendendo ao parecer 196/96 do Conselho Nacional de Saúde ${ }^{(20)}$.

A análise dos dados foi feita de acordo com a sistematização proposta por Spink ${ }^{(18,21)}$ associada à Teoria do Núcleo Central ${ }^{(22)}$ Que é considerada uma abordagem complementar à teoria mais ampla (representação social). Essa sistematização abrange as seguintes etapas: transcrição das entrevistas; leitura flutuante do material, intercalando a escuta do material gravado com a leitura do material transcrito; atentar para versões contraditórias, detalhes sutis como silêncios, hesitações, esquecimentos, risos e entonação da voz; mapeamento dos temas emergentes; construção do discurso: retornar aos objetivos da pesquisa para definir claramente o objeto da representação; definição do Que é "pano de fundo" e "figura"; levantar as principais dimensões da representação; construção dos mapas Que transcrevem toda a entrevista, respeitando a ordem do discurso. Os mapas possibilitam a visualização da relação, associação de idéias entre as dimensões; transportar estas associações para um gráfico (árvore da representação), pontuando as relações entre elementos cognitivos, as práticas e os investimentos afetivos.

A partir dessa sistematização e da teoria do núcleo central foi construída a "árvore máxima” da representação (Figura I).

\section{RESULTADOS E DICUSSÃO}

A "árvore máxima” apresentada na Figura 1 contém o núcleo central (relação estudante-cliente) e os elementos periféricos Que se constituem em dois principais ramos de representações: "A tríade igualdade/diferença/desigualdade de gênero" e "A falta de preparo: a lacuna no ensino".

As narrativas das estudantes representam como a equipe de enfermagem atende um cliente homossexual, pois, segundo ela, sentia Que o cliente era discriminado e que os membros da equipe de enfermagem tinham receio de chegar perto e de tocar (usou-se o termo "das estudantes" Quando o texto se refere especificamente ao gênero feminino. O mesmo sentido se aplica ao gênero masculino. Quando o texto considera ambos os gêneros, utilizamos "os" e "as)".

As diferenças, tanto físicas Quanto comportamentais, são percebidas e, algumas delas, podem gerar uma assistência incompleta e inadequada. As narrativas a seguir representam tal percepção:

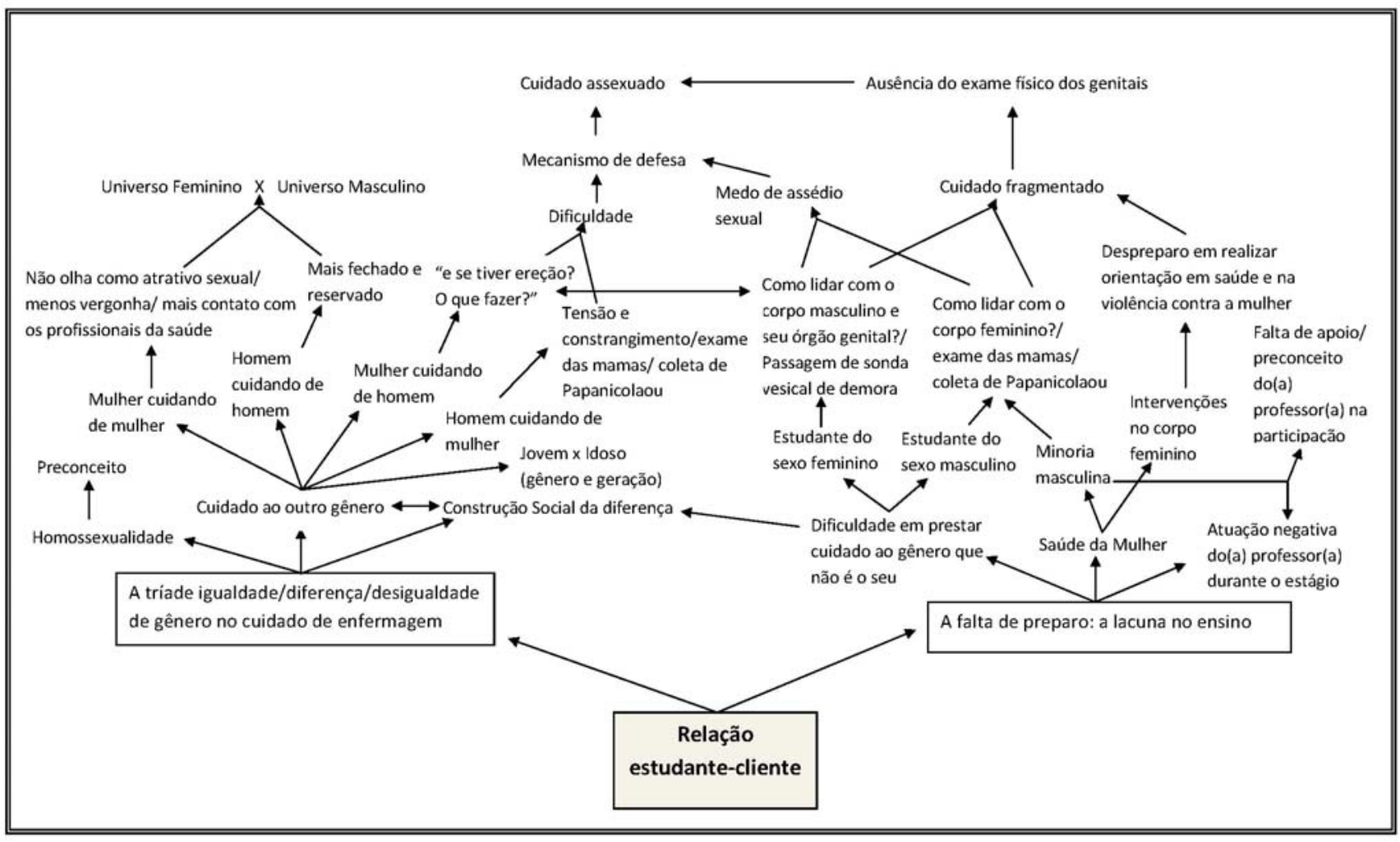

Figura 1. Árvore máxima da Representação Social de estudantes de enfermagem sobre a relação estudante-cliente pela ótica da categoria de gênero, na prática do cuidado de enfermagem. 
Se a pessoa é homossexual, por exemplo, tem a sua vida, eu não vou discutir se a pessoa é ou não é, a vida sexual dela, porQue isso é íntimo dela. E, a figura, a área do corpo, os genitais e a boca, $o$ Que a pessoa usa ou deixa de usar, eu não vou discutir isso. (E6, F, $4^{\mathrm{a}}$ série, I)

Eu acho Que eu já encontrei muita gente diferente, já fiz estágios, já encontrei homossexuais, já encontrei pessoas com HIV, já encontrei gente de tudo Quanto é tipo, gente recatada, gente depravada. Depravado que eu falo assim é aquele sem limites, dá para QualQuer um, Quantas vezes Quer, sem limites. Não assim "Ah, esse cara é depravado". Não julgando, mas uma pessoa sem limites. (E6, F, 4ª série, I)

A análise da primeira narrativa expõe Que a não discussão pode significar a desconsideração do cuidado voltado para a orientação em saúde sexual. A percepção Que a estudante teve da orientação do desejo sexual do cliente, diferente da sua, pode revelar um despreparo em lidar com Questões de gênero e diversidade sexual.

No tocante dessa narrativa, torna-se relevante trazer à discussão uma ética feminista, defendida por Lunardi ${ }^{(23)}$. Segundo esta autora, em nossa sociedade e, especificamente, na saúde e na enfermagem, de modo predominante, estão presentes muitas relações de desigualdade, seja entre os(a) trabalhadores(a), seja entre estes(as) e os(as) clientes, o Que requer não uma ética pautada na neutralidade, no tratamento da desigualdade apenas como diferença, mas uma ética comprometida com a maioria dos Que se encontram em situação de opressão. A opção pela ética feminista significa a opção pelo enfrentamento da superação de relações opressivas e desiguais em QualQuer campo e dimensão social.

Pela segunda narrativa a percepção da diferença leva a uma dimensão de desigualdade no cuidado pela consideração preconceituosa ("depravado, "sem limites) do cliente. A expressão do preconceito tanto é realizada de forma implícita, observado na última narrativa, Quanto de forma explícita:

Eu acho que infelizmente eu ainda tenho preconceito, infelizmente. Eu vou tentar, eu vou conseguir trabalhar isso, porque eu penso de uma forma que eu não gostaria de pensar que é "Se tem HIV, muita coisa errada ele fez, se não foi por transar sem camisinha foi por promiscuidade, se não foi assim foi usando droga injetável com a mesma seringa o Que é pior. Então, eu acho assim, eu fico pensando assim "Que pessoa errada, estava merecendo mesmo passar por isso". E eu depois paro para pensar, eu falo "Não acredito Que eu, uma Quase enfermeira está pensando e falando dessa forma, não, tem Que mudar, eu vou tentar mudar e eu vou mudar, porque eu acho você pensar dessa forma. ", mas infelizmente eu ainda penso desse jeito, mas eu vou mudar. (E6, F, 4ª série, II)

A partir dessas narrativas suscita a seguinte Questão: como os (as) estudantes de enfermagem, futuros (as) enfermeiros (as) e educadores (as) em saúde expressarão os ideários de saúde livres de preconceitos de gênero? Infelizmente, nos limites deste trabalho, os resultados expressam que suas práticas atuais já contêm elementos preconceituosos Que interferem em uma assistência integralizada.

Os estereótipos sexistas se referem às práticas e representações, ideologias e aos preconceitos. Eles funcionam em relação às mulheres para atribuir-lhes Qualidades consideradas inferiores em relação aos homens. E, na perspectiva representada pela narrativa da estudante, o estereótipo sexista também abrange as conotações referidas para as pessoas com orientação do desejo sexual e/ou práticas sexuais consideradas diferentes da tradicionalmente conhecida, ou seja, heterossexual $^{(24)}$.

A partir do que foi exposto, apreende-se que o corpo do cliente não é percebido pela estudante apenas como um corpo doente ou saudável. A doença também é construída a partir de conceitos anteriores, os Quais sexualidade, gênero e orientação do desejo sexual se fazem presentes.

Os corpos são significados pela cultura e são por ela alterados. Devemos problematizar como determinada característica passou a ser reconhecida e significada como uma 'marca' - como, por exemplo, o pênis, a vulva, os pêlos, os músculos - definindo uma determinada identidade. Além disso, também se deve problematizar Quais os significados Que, nesse momento e nessa cultura, estão sendo atribuídos a tal marca ou a tal aparência, pois pode ocorrer Que os desejos e as necessidades Que alguém experimenta estejam em discordância com a aparência de seu corpo ${ }^{(25)}$.

A partir dessa perspectiva, uma forma de sexualidade é generalizada e naturalizada, além de funcionar como referência para todo o campo e para todos os sujeitos. A heterossexualidade é concebida como "natural" e também como universal e normal. Aparentemente supõese Que todos os sujeitos tenham uma inclinação inata para eleger como objeto de seu desejo, como parceiro de seus afetos e de seus jogos sexuais alguém do sexo oposto ${ }^{(25)}$. Consequentemente, as outras formas de sexualidade são constituídas como antinaturais, peculiares e anormais.

Desta forma, essa heterossexualidade presumida, segundo a narrativa da estudante, aparece como um padrão assumido pelos(as) estudantes como sinônimo de normal, e consequentemente, tudo Que foge a esse padrão heterossexual é doença ou desvio.

A sociedade busca, intencionalmente, através de múltiplas estratégias e táticas, "fixar" uma identidade masculina ou feminina "normal" e duradoura. Esse intento articula, então, as identidades de gênero "normais" a um único modelo de identidade sexual: a identidade heterossexual ${ }^{(25)}$.

Nessa perspectiva, deve-se ampliar a compreensão do ser humano para não ser visto apenas como um corpo onde a saúde ou a doença se instalam. Por essa razão, torna-se necessário o entendimento de Que o (a) cliente precisa ser cuidado (a) na sua totalidade, o Que implica discutir as categorias que o compõem, tais como etnia, classe, gênero, sexualidade, geração, nacionalidade e religião.

O elemento periférico "construção social da diferença”, aborda os seguintes discursos das estudantes de enfermagem:

A gente sabe Que o homem tem um pênis e a mulher não tem, mas como lidar com ele? Como na sua prática, você vai poder pegar sem causar constrangimento para ele e para você? (E3, F, 2 ${ }^{\mathrm{a}}$ série)

Eu só tenho irmã, mulher em casa, eu nunca vi homem pelado. Eu nunca tive relacionamento sexual com ninguém. Eu acho que é próprio do ser humano, senão não iria se vestir né. Se não tivesse tanta vergonha a gente iria andar pelado pelo mundo "eh, que beleza”. Então, é próprio, é aquela coisa que você tem. E aí na 
hora, eu não consegui ver o paciente como algo sexuado, mas como alguém que está precisando de você. Não sei, eu não consegui ver um ser sexuado lá. (E4, F, 2ª série)

A partir da narrativa exposta anteriormente, percebe-se que o gênero nos leva a considerar Que as próprias instituições, os símbolos, as normas, os conhecimentos, as leis e políticas de uma sociedade são constituídas e atravessadas por representações e pressupostos de feminino e de masculino e, ao mesmo tempo, produzem e/ou ressignificam essas representações ${ }^{(26)}$.

Desta forma, é importante Que se reconheça Que as diversas instituições sociais, entre elas a escola, não apenas reproduz ou reflete as concepções de gênero e sexualidade Que circulam na sociedade, mas também Que ela própria as produz. Tal fato pode ser exemplificado pela seguinte afirmação Que objetiva a diferenciação sexual: "Meninos têm pênis... e meninas têm vagina"(27).

Pelas representações das estudantes, apreende Que o gênero constrói o sexo, pois a partir de uma diferença sexual (genitália) são construídas as características consideradas masculinas e femininas. $\mathrm{O}$ Que se percebe como diferença pode se caracterizar numa dimensão de igualdade ou desigualdade no cuidado. Porém, pelos discursos das estudantes de enfermagem, a representação dessa diferença é caracterizada da seguinte forma:

É porque a gente é criada assim, com essa diferença. O menino é o homenzinho, namorador, tem que sair pra provar que é homem. E a menina não, a menina é mais na dela, ela tem que se comportar, ela não pode se misturar muito com os meninos, porque senão já é moleque. (E I4, F, 3ª série)

Eu acho Que todas as pessoas têm fisiologicamente desejo sexual, mas eu acho que mais em relação aos homens que eles têm realmente essa necessidade de ter relações sexuais não sei Quantas vezes por semana, por mês, dizem assim, cultural do homem ter mais desejo do que a mulher. (E9, F, 4ª série)

No tocante a essas narrativas, percebe-se Que ser homem ou ser mulher corresponde a pertencer ao gênero masculino ou feminino. Tal relação de pertencimento a um gênero prevê a negação e o distanciamento ao sexo que não é o seu, o chamado sexo "oposto"(28).

Os resultados desta pesquisa expressam Que o elemento periférico "cuidado ao outro gênero" é representado pela facilidade Que o (a) estudante de enfermagem tem ao cuidar um(a) cliente Que possua o mesmo gênero Que o seu. A seguir são apresentadas as narrativas correspondentes aos elementos periféricos "mulher cuidando de mulher", "mulher cuidando de homem", "homem cuidando de homem" e "homem cuidando de mulher".

Acho Que se fosse mulher não teria tanto problema, porque mulher com mulher é normal, agora por ser homem, porQue para passar sonda você tem Que pegar o pênis do paciente, essa é a parte chata, você tem que literalmente pegar inteiro, acho que isso é a parte mais chata, e o homem também fica constrangido por ser uma menina novinha, aluna, ele também fica constrangido, você percebe isso. É nesse fato o contato direto que é complicado, Que eu achava, agora não tem mais problema. (E8, F, 4ª série)
Às vezes, o homem erotiza o toque. É muito complicado. Eu não sabia como lidar, por exemplo, se eu estivesse que passar uma sonda em homem e o cara tivesse uma ereção. (E I I , F, 4ª série, I)

Eu acho Que com o homem é mais natural, é mais natural porque, assim, teoricamente ele tem o mesmo sexo que você, eu acho Que ele se sente mais a vontade, passa mais segurança pra você. Agora mulher, você vê que ela fica mais constrangida, ela fica mais envergonhada. Ela vai passar essa insegurança pra você, e você vai se sentir invadindo a intimidade dela. Mas no homem por esse lance de igualdade, de sexo né, você fica mais tranquilo. (E7, M, 4a série)

Eu procuro ficar calmo, porQue principalmente quando é mulher você fica meio tenso, mas eu procuro respirar fundo, eu procuro colocar na minha cabeça Que é um procedimento, Que tem uma finalidade e presto o cuidado na boa assim. (E7, M, 4ª série)

Essas narrativas demonstram a representação histórica do cuidado com o corpo humano demarcado pelo rompimento entre os conceitos de sagrado e profano, estabelecidos pelo Cristianismo, impossibilitando o acesso a áreas "proibidas", como os órgãos sexuais. A realização de procedimentos técnicos ao corpo, só era possível por meio de instrumentais, como forma de manter a impessoalidade e a distância necessária para a não contaminação com o corpo profano e pecaminoso $^{(29)}$.

Essa discussão nos remete à categoria sexualidade, considerada um tabu e, portanto, marginal na enfermagem por ser relacionada nas áreas biológica e biomédicas com as dimensões do ato sexual e da reprodução. Tal perspectiva biologicista estendeu-se à formação dos profissionais da área da saúde e concentra-se fixa na dimensão da genitalidade, o que é uma das tantas dimensões Que constituem a sexualidade ${ }^{(30)}$.

Ao lidar com o corpo masculino, a estudante adeuire certas formas de defesa para lidar com sua dificuldade e constrangimento, como "vestir uma máscara de cara de pau", "vou encarar isso como profissional mesmo", "não vou colocar nada de sentimentos". A partir da criação dessas formas de defesa, a estudante deixa de prestar um cuidado integral ao cliente, caracterizando sua assistência de enfermagem em um cuidado fragmentado e assexuado.

Segundo as narrativas das estudantes de enfermagem, cuidar de mulher é melhor e mais fácil, pois elas conhecem o corpo feminino. Porém, cuidar de um homem acarretaria dificuldade pela representação de que o homem "é mais fechado", "se reserva mais do que a mulher", "não conta suas emoções, por essa Questão do machismo". Essa dificuldade em prestar cuidado ao gênero Que não é o seu é representada pela idéia de que o "homem é o sexo oposto, tem sentimento diferente do que numa mulher".

As representações dos (as) estudantes de enfermagem expõem a necessidade de desconstruir a oposição binária existente entre o masculino e o feminino nas práticas do cuidado de enfermagem, nas Quais as estudantes diferenciam o cuidado prestado ao cliente do gênero masculino, assim como o faz o estudante ao cuidar de uma cliente ${ }^{(31)}$.

As narrativas dos (as) estudantes representam "a mulher" e "o homem" como categorias homogêneas e excludentes, porém existem muitas e conflitantes formas de definir e viver a feminilidade e a 
masculinidade. Desta forma, o conceito de gênero enfatiza essa pluralidade e conflitualidade dos processos pelos Quais a cultura constrói e distingue corpos e sujeitos femininos e masculinos, tornando-se necessário admitir Que isso se expressa pela articulação de gênero com outras categorias sociais, tais como classe, raça/etnia, sexualidade, geração, religião, nacionalidade ${ }^{(26)}$.

Dentro das relações de gênero entre estudante e cliente, o (a) estudante representa uma diferenciação do Que é considerado universo masculino polarizado ao universo feminino. Em nenhum momento das narrativas dos (as) estudantes foi expressa a palavra "gênero", o Que pode refletir, no âmbito deste estudo, um desconhecimento dessa categoria de estudo, assim como uma lacuna no ensino de enfermagem. Os (as) estudantes representam as diferenças sexuais percebidas nas relações como os (as) clientes, porém não percebem Que a prática profissional da enfermagem é permeada pelas relações de gênero.

Gênero é a organização social da diferença sexual. O Que não significa Que gênero reflita ou implemente diferenças físicas fixas e naturais entre homens e mulheres, mas sim Que gênero é o saber Que estabelece significados para as diferenças corporais. Esses significados variam de acordo com as culturas, os grupos sociais e no tempo, pois nada no corpo, incluindo os órgãos reprodutivos femininos, determina univocamente como a divisão social será definida ${ }^{(32)}$

O eixo temático "A falta de preparo: a lacuna no ensino" revela tanto uma falta de preparo por parte dos docentes em lidar com o tema corpo/gênero/sexualidade Quanto por parte dos (as) estudantes. Essa falta de preparo é representada por uma lacuna no ensino, pois não há um ambiente Que proporcione ao (à) estudante de enfermagem expressar suas dificuldades e sentimentos.

Os estudantes de enfermagem ao realizarem o exame de Papanicolaou representaram a atuação do (a) professor (a) como um obstáculo que impede as práticas do estágio, ou mesmo sua ausência como fator negativo, correspondendo a um preconceito de gênero:

"E o que eu senti falta foi da presença da professora nesse sentido. Ela tinha um certo preconceito já com o homem em relação a essa Questão e ela tentou de todas as formas impedir a nossa participação nas coletas, não deu nenhum apoio em nenhum momento. A gente conversou com ela, a gente Quer aprender, a gente Quer fazer, a gente Quer estar lá junto, ela falava não e Que as mulheres ficavam inibidas". (E 10, M, 4ª série)

Corroborando com esta representação, encontra-se respaldo na tese de Nascimento ${ }^{(7)}$, a Qual disserta sobre a "consciência de gênero" e ensino de enfermagem das mulheres-enfermeiras-professoras, um estudo da reprodução de relações (desiguais) de gênero. Embora Nascimento faça uso da expressão "consciência de gênero", prefiro substituí-la para a expressão "desconsideração das relações de gênero", pois "consciência” envolve percepção, idéia, compreensão ou conhecimento daquilo que se passa e a capacidade crítica de avaliar um dado. Assim, acredito que os(as) professores(as) não estão preparados(as) para trabalhar com essas Questões devido ao desconhecimento da utilização da categoria gênero nos discursos e nas práticas de cuidado em saúde.

Desta forma, a desconsideração das relações de gênero pelos (as) professores (as) apresenta-se de um modo tal Que não lhes permite o desenvolvimento da crítica à dominação de gênero. Em conseQüência, os(as) professores(as) reproduzem relações desiguais de gênero no exercício de sua prática docente capazes de manter a subordinação/ submissão das enfermeiras Quando no exercício profissional. No estudo de Nascimento, foi possível depreender dos relatos das professoras a idéia difundida na enfermagem de Que, no exercício profissional, tanto o pessoal Que trabalha na área da saúde Quanto os pacientes expressam sua sexualidade $e^{(7)}$.

A falta de pesquisas sobre o papel do homem na enfermagem tem deixado de trazer a experiência vivenciada por estudantes e profissionais sobre como se dá a compreensão e a incorporação desse papel durante a formação e a vida profissional(33). Assim, o estudante de enfermagem se sente despreparado em certas disciplinas da grade curricular, conforme pode ser observado na narrativa a seguir:

Eu acho Que tem uma inexperiência, a gente não teve aula de como abordar essas intercorrências, alguma técnica pra ficar despreocupado, pra onde olhar durante o exame. Podia dar dicas porque nós somos inexperientes, "não faça esse tipo de pergunta". Por exemplo, eu não sabia, na primeira paciente, se "tira a roupa", "tira a vestimenta" ou "por favor, eu vou te examinar". Eu tentava falar delicadamente "Olha, por favor, senhora, poderia tirar a vestimenta?", aí na outra "Você poderia tirar a saia?". Você não sabe qual a melhor pergunta na hora. Eu acho que faltou também um pouco de psicologia. (E 12, M, 2ª série)

Diante da dificuldade expressa pelos estudantes de enfermagem, torna-se importante expor a discussão do uso do artigo gramatical masculino em alguns textos e o uso do artigo gramatical feminino em outros. Assim, como a enfermagem era anteriormente só feminina, justificava o uso do feminino. No entanto, Quando entraram os homens, principalmente nas forças armadas, começou a usar, também, o artigo masculino. Essas percepções e dificuldades em romper com tal esquema opressivo fizeram com Que até bem pouco tempo atrás, e ainda em muitos estudos atuais, ao traçar alguma referência ao profissional de enfermagem por escrito ou verbalmente, fosse utilizado o termo enfermeiro, como uma forma de reforçar uma identidade pública superior masculina ${ }^{(34)}$.

Uma das formas da grande confusão de identidade na enfermagem entre o binômio (enfermeiro-enfermeira) mostra Que identidades sexuais, e não basicamente de gênero, formam um agir e falar como enfermeiro, para legitimar a prática como poder. Porém, como a prática é essencialmente feminina, mantém-se o papel submisso, apesar da utilização do termo no masculino ${ }^{(34)}$.

A partir dessa discussão, o elemento periférico "medo de assédio sexual" desvela as representações ao Que tange tanto por um receio por parte dos(as) estudantes de enfermagem em sofrerem assédio sexual provenientes dos(as) clientes, Quanto por um receio de cometerem assédio sexual na prática do cuidado de enfermagem, no Que tange aos cuidados nos genitais e procedimentos Que envolvem a invasão da privacidade e intimidade do(a) cliente.

O medo de cometer ou sofrer assédio sexual é representado pelas seguintes narrativas:

Eu tenho medo da pessoa interpretar o toque da forma Que não é para interpretar, porque eu estou trabalhando, estou fazendo alguma coisa que de alguma forma é terapêutica para esse paciente. $E$ 
muitas vezes, não sei... Já ouvi relatos de umas colegas que nunca aconteceu, mas muitas vezes, a pessoa te chama pra sair, depois... Porque acha que aquele toque significou alguma coisa. Comigo, nunca aconteceu. Espero Que nunca aconteça porQue acho extremamente constrangedor, extremamente desrespeitoso... Você está trabalhando. (E I l, F, 4ª série, I)

E já aconteceu assim comigo de paciente, tipo, eu estava cuidando dele e o paciente do lado, que era muito próximo, e o paciente começou a fazer gracinha, a chamar de tchutchuca, uns nomes assim... começar mesmo a partir pro modo sexual da coisa, de enfermeira, aquela imagem da enfermeira erótica. E aí eu chamei minha professora, eu estava no segundo ano, chamei a professora e conversou com o paciente, falou Que a gente estava lá pra fazer nosso trabalho, Que era um trabalho sério. (E9, F, 4a série)

Segundo as representações das estudantes apreendem-se situações caracterizadas por violência de gênero, Que pode ser entendida por relações assimétricas de poder entre homens e mulheres, nas Quais a mulher freqüentemente encontra-se em situação de subordinação ${ }^{(35)}$.

Em um estudo realizado por Oliveira e D'Oliveira ${ }^{(35)}$, Que teve como sujeitos 179 profissionais de enfermagem de um hospital geral, revelou Que uma em cada três $(33,3 \%)$ mulheres referiu violência física ao menos uma vez na vida. A violência sexual, considerada grave em todas as suas expressões, foi referida por $28,2 \%$ das mulheres, sendo $4 \mathrm{I}(23,2 \%)$ relatos referentes à relação sexual forçada.

Os principais agressores para a violência psicológica foram na maioria dos casos os homens colegas de trabalho $(39,7 \%)$ e chefia $(23,5 \%)$. Os principais agressores da violência física foram pacientes e acompanhantes $(47,7 \%)$ e estranhos (36,8\%); para violência sexual $42,8 \%$ foram de pacientes e acompanhantes e $57,1 \%$ foram de estranhos. Colegas de trabalho e chefias não foram relacionados a nenhum caso de violência física e/ou sexual ${ }^{(35)}$.

Quanto à revelação, estudos apontam a sub-informação das experiências de violência nas relações de intimidade por ser uma situação estigmatizante, envolvendo vergonha e medo. A violência por outros agressores representou a segunda maior taxa de violência. O ambiente de trabalho foi o principal locus da violência psicológica cometida, majoritariamente, por colegas de trabalho, chefia e pacientes/acompanhantes ${ }^{(35)}$.

A partir da análise das representações sobre o elemento periférico "medo de assédio sexual", percebeu-se uma necessidade dos(as) estudantes de mecanismos de defesa para manipular as situações constrangedoras vivenciadas na prática do cuidado de enfermagem. Dentre os mecanismos de defesa observou-se uma representação de configurações pertinentes a uma possível divisão sexual nos procedimentos de enfermagem resultantes da prestação de cuidados Que implicam a exposição dos genitais das (os) clientes. No Que tange a esses cuidados específicos, os(as) estudantes tentam se precaver e se respaldar a partir da presença de uma pessoa Que possua o mesmo gênero que o(a) cliente:

Eu acredito muito que o ser humano tenha uma boa fé, existem pessoas boas, só Que também têm pessoas Que não tem uma boa índole Que agem de má fé. E eu já vi alguns relatos, em entrevistas, em jornais, de pacientes que entram em processo, processam colegas da gente, enfermeiros, por assédio sexual ou por atentado ao pudor. Então, se você está num exame íntimo, está você e a paciente, de repente, é claro, a gente nunca está esperando isso, de repente, vai Que aquela paciente, no exame, ela ache que você fez algo Que não deveria ter feito, então Quem vai provar Que você não fez nada daquilo. Se for outro homem podem alegar Que vocês dois, um homem ajuda outro homem e juntos com a paciente, então por isso que eu procuro estar com uma mulher do meu lado, uma auxiliar de enfermagem, porque ela fica do meu lado, me auxilia com o material, para preencher as lâminas, pra realmente, se a paciente falar alguma coisa eu tenho uma pessoa Que testemunhe todo o exame. Eu recomendo aos meus colegas que estão se formando é Que façam sempre o exame ginecológico com outra pessoa do lado. (E8, M, 4ª série)

Durante o período dos estágios os(as) estudantes estão acostumados(as) a colherem a histórica clínica do(a) cliente e reunir dados do prontuário, sinais vitais, exames laboratoriais e de imagens, para apresentar um estudo de caso do(a) cliente Que estão cuidando. $\mathrm{O}$ caso é discutido perante o exame minucioso da doença. $\mathrm{O}$ planejamento dos cuidados é traçado a partir da sistematização da assistência de enfermagem (SAE). Porém, não há a discussão de casos Que contemplem essas experiências vivenciadas pelos (as) estudantes e as subjetividades Que emergem em cada situação. Assim, gênero e sexualidade, como outras categorias, estão nas margens da grade curricular de enfermagem.

O elemento periférico, "Saúde da Mulher", emerge do eixo "A falta de preparo: a lacuna no ensino", pois os (as) estudantes de enfermagem representam o corpo da mulher para além do que é considerado no discurso da área da saúde, o Qual expressa o corpo da mulher como invólucro sexual para atividades reprodutivas. Desta forma, os (as) estudantes de enfermagem percebem as subjetividades Que emergem na relação com a cliente, porém não recebem preparo para lidar com elas, especialmente ao testemunhar um momento de violência contra a mulher:

Eu não peguei nenhum parto feito por enfermeira, eu só peguei parto pelo médico, mas eu acho Que... foi horrível, a paciente extremamente exposta e o linguajar com a paciente é horrível, de falar "Tá vendo, não foi bom fazer?", isso não foi uma vez só Que eu ouvi. Outro caso foi de falar assim para a paciente "Tá vendo, foi comer, tá gorda igual um hipopótamo, agora está tendo um hipopotamozinho", nem sei como se fala. E assim, um desrespeito com o paciente e aí, eu sempre me coloco se fosse eu, eu fico muito chateada de ver Quando fazem isso com os pacientes, porque se põe na situação e dá uma tristeza muito grande, em relação ao profissional, o descrédito em relação a você se colocar na mão de um profissional Que vai fazer um comentário sobre você depois, Que não vai te respeitar, é muito triste isso. (E3, F, $3^{\text {a }}$ série)

A partir dessa narrativa, torna-se importante citar o Programa de Assistência Integral à Saúde da Mulher (PAISM), formulado em 1983 pelo Ministério da Saúde. Esse programa tem como proposta a ampliação da atenção à mulher e novas formas de relacionamento Que deve basear-se no respeito mútuo, no diálogo e na transmissão de informações Que dizem respeito à saúde integral da mulher. Esses 
itens foram inspirados no ideário da autonomia e integralidade da pessoa, Que tem como um dos pontos importantes a apropriação do conhecimento sobre seu corpo. Esse conceito contém a proposta de uma ruptura com normas e leis heterônimas Que sempre definiram e controlaram o corpo feminino ${ }^{(14)}$.

Porém, o Que se observa na representação da estudante de enfermagem sobre a atuação da equipe de saúde é o contrário da proposta do PAISM, principalmente na violência psicológica sofrida pela cliente por meio da linguagem estabelecida pelos (as) profissionais da equipe de saúde.

Desta forma, é na linguagem Que operam os sistemas simbólicos Que nos permitem entender nossas experiências e definir aquilo Que nós somos ou pensamos ser. Todas as práticas de significação e os processos simbólicos através dos Quais os significados são construídos envolvem relações de poder: o poder de nomear, de descrever, de classificar, de identificar, de diferenciar, o poder de definir, enfim, Quem está incluído e Quem está excluído ${ }^{(36)}$.

\section{CONSIDERAÇÕES FINAIS}

Esta pesquisa permitiu desvelar elementos importantes das representações sociais dos(as) estudantes de enfermagem acerca do(a) cliente para compreender as construções sociais sobre os objetos sociais (clientes) e a apropriação que faz o sujeito (estudantes) destas construções, ao utilizar como lente a categoria gênero.

Os resultados apresentam representações das categorias masculino e feminino como homogêneas. Porém, essa representação se torna limitada ao expor as práticas de cuidado que os(as) estudantes vivenciam em seus estágios e na relação entre o(a) cliente. A polaridade masculino-feminino revela uma divisão binária que é considerada uma forma limitada da visão do mundo, a partir de duas posições.
Assim, o padrão de ver o mundo pode ser caracterizado pelas seguintes posições: homem, branco, de classe média, heterossexual. Porém, a sociedade é múltipla por meio da variedade das intersecções das diversas categorias.

O processo de objetivação e ancoragem das representações sociais dos(as) estudantes de enfermagem sobre a relação com o(a) cliente na prática do cuidado revelou Que o(a) estudante representa o(a) cliente como ser assexuado, porém ao representar as diversas situações na relação com o(a) cliente em situações constrangedoras, revelam um discurso Que assemelha a enfermagem com as imagens polarizadas na dicotomia Eva/Maria, no passado, e no presente pelas imagens metafóricas de "enfermeira do funk" e seu pólo oposto, "anjo assexuado".

Este estudo, ao conhecer como se expressam e se desenvolvem as relações de gênero nas narrativas dos(as) estudantes de enfermagem a partir de suas representações sobre a relação com a(o) cliente no universo do cuidado, fornece conhecimento para transcender a oposição binária sem desvalorizar, ou supervalorizar, o masculino e o feminino, e a construção de relações de gênero nas Quais o feminino e o masculino não fossem polarizados e hierarQuizados, de modo a resultarem em desigualdades no contexto na saúde.

A partir dessas Questões e pela árvore máxima apresentada, percebe-se a necessidade de trabalhar concomitantemente com as categorias corpo, gênero e sexualidade. Essa interface propicia o enriQuecimento de discussões acadêmicas e pode ser compreendia, no âmbito deste estudo, como campo de conhecimento da saúde e da enfermagem como uma prática de relações, na Qual o(a) profissional de saúde está inserido(a) em um contexto historicamente determinado. Em tal contexto, trabalha-se com representações simbólicas, para muito além de corpos estáticos, fragmentados, assexuados e desprovidos de gênero.

\section{REFERÊNCIAS}

I. Lopes MJM. O sexo do hospital. In: Lopes MJM, Meyer DE, Waldow VR. Gênero e Saúde. Porto Alegre: Artes Médicas, 1996. p. 76-105.

2. Waldow VR. Cuidar: expressão humanizadora da enfermagem. $2^{\text {a }}$ ed. Petrópolis: Vozes; 2007.

3. Bandeira L, Oliveira EM. Representações de gênero e moralidade na prática profissional da enfermagem. Rev Bras Enferm 1998 5 I (4): 677-96

4. Oliveira EM. A mulher, a sexualidade e o trabalho. São Paulo: Hucitec; 1999

5. Meyer DE. Reproduzindo relações de poder, de gênero e de classe no ensino de enfermagem [dissertação]. Porto Alegre: Universidade Federal do Rio Grande do Sul. Faculdade de Educação; 1991.

6. Meyer DE. Teorias e políticas de gênero: fragmentos históricos e desafios atuais. Rev Bras enferm 2004; 57(1): 13-8.

7. Nascimento ER. Consciência de gênero e ensino de enfermagem: estudo de relações (desiguais) de gênero [dissertação]. Salvador: Universidade Federal da Bahia, Escola de Enfermagem; 1994.

8. Ferreira SL, Nascimento ER. Transversalidade de conteúdos nas diretrizes curriculares: o gênero no ensino da enfermagem. Rev Bras Enferm 2004; 57(1): 71-4.

9. Lunardi VL. Relacionando enfermagem, gênero e formação disciplinar. Rev Bras Enferm 1993; 46(3/4): 286-95.

10. Rizzotto MLF. A Questão de gênero e suas implicações na formação das enfermeiras brasileiras. Esc Anna Nery Rev Enferm 1998; 2(3): 45-54.

I1. Ojeda BS, Eidt AR, Canabarro S, Corbellini VL, Creutzberg M. Saberes e verdades acerca da enfermagem: discursos de alunos ingressantes. Rev Bras Enferm 2008; 6 I (1): 78-84.

12. Lessa GM. Consciência de gênero: desenvolvimento no currículo de graduação em enfermagem. Universidade Federal da Bahia. Escola de Enfermagem: Salvador; 1998.

13. Parga EJS, Sousa JHM, Costa MC. Estereótipos e preconceitos de gênero entre estudantes de enfermagem da UFBA. Rev Baiana Enferm 200 I; 14(1): 107-15.

14. Oliveira EM. A contribuição do ensino das Ciências Sociais na Enfermagem. Acta Paul Enferm 1998; I I (1): 88-94.

15. Lima RC, Brêtas JRS. Estudo comparativo entre séries de graduação em enfermagem: representações dos cuidados ao corpo do cliente. Acta Paul Enferm 2006; 19(4): 379-86.

16. Bison RAP, Furegato ARF. As representações sociais dos estudantes de Enfermagem sobre sexualidade. Rev Enferm UERI 2002; 10(3): : 82-6.

17. Moscovici S. Representações Sociais: investigações em psicologia social. Petrópolis: Vozes; 2003.

18. Sá CP. O conceito e o estado atual da teoria. In: Spink MJ, organizador. O conhecimento no cotidiano: as representações 
sociais na perspectiva da psicologia social. São Paulo: Brasiliense; 2004. p. 19-45.

19. Arruda A. Teoria das Representações Sociais e Teorias de Gênero. Cad Pesquisa 2002; (1 17 ): 127-47.

20. Ministério da Saúde (BR). Conselho Nacional de Saúde. Resolução $n^{\circ}$ 196/96. Diretrizes e normas regulamentadoras sobre pesquisas envolvendo seres humanos. Brasília: Ministério da saúde; 1996.

21. Spink MJ. Desvendo as teorias implícitas: uma metodologia de análise das Representações Sociais. In: Guareschi P, Jovchelovitch S, organizadores. Textos em Representações Sociais. Petrópolis: Vozes; 1998.

22. Sá CP. Sobre o núcleo central das representações sociais. Petrópolis: Vozes; 1996.

23. Lunardi VL, Lunardi Filho WD. A ética feminista como um instrumental teórico para a ética na saúde e na enfermagem. Texto Contexto Enferm 2003; 12(3): 383-6.

24. Michel A. Não aos estereótipos. Vencer o sexismo nos livros para as crianças e nos manuais escolares. São Paulo: Conselho Estadual da Condição Feminina; 1989.

25. Louro GL. Pedagogias da sexualidade. In: Louro GL, organizadora. O corpo educado: pedagogias da sexualidade. Belo Horizonte: Autêntica; 2007. p. 7-34.

26. Meyer DE. Gênero e educação: teoria e política. In: Louro GL, Felipe I, Goellner SV, organizadores. Corpo, gênero e sexualidade: um debate contemporâneo na educação. Petrópolis: Vozes, 2007. p. 9-40.
27. Furlani J. Educação sexual: possibilidades didáticas. In: Louro GL, Felipe I, Goellner SV, organizadores. Corpo, gênero e sexualidade: um debate contemporâneo na educação. Petrópolis: Vozes; 2007. p. 66-81.

28. Auad D. Educar meninas e meninos: relações de gênero na escola. São Paulo: Contexto; 2006.

29. Colpo IC, Camargo VC, Mattos SA. A imagem corporal da enfermeira como objeto sexual na mídia: um assédio a profissão. Cogitare Enferm 2006; I I (1): 67-72.

30. Ressel LB, Gualda DMR. A sexualidade na assistência de Enfermagem: reflexões numa perspectiva cultural. Rev Gaúcha Enferm 2004; 25(3): 324-33.

31. Scott J. Gender: An useful category of historical analyses. Gender and the politics of history. New York: Columbia University Press; 1989.

32. Scott IW. Prefácio a Gender and politics of History. Cad Pagu 1994; (3): 11-27.

33. Pereira A. A representação do gênero masculino na enfermagem. Rev Enferm UERJ 1996; 4(2): 2 I I-9.

34. Padilha MICS, Vaghetti HH, Brodersen G. Gênero e enfermagem: uma análise reflexiva. Rev Enferm UERJ 2006; I 4(2): 292-300.

35. Oliveira, AR, D'Oliveira AFPL. Violência de gênero contra trabalhadoras de enfermagem em hospital geral de São Paulo (SP). Rev Saúde Pública 2008; 42(5): 868-76.

36. Meyer DE. Cuidado e diferença: da integralidade à fragmentação do ser. Rev Gaúcha Enferm 200 I; 22(2): 2 1-38. 